Journal of Management and Bussines (JOMB)

Volume 2, Nomor 1, Juni 2020

p-ISSN : 2656-8918

e-ISSN:2684-8317

DOI : https://doi.org/10.31539/jomb.v2i1.657

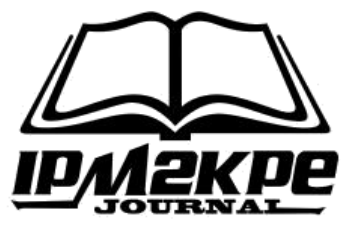

\title{
KEKUATAN SOCIAL MEDIA DAN WORD OF MOUTH DALAM MEMPENGARUHI KEPUTUSAN PEMBELIAN KONSUMEN PADA RESTORANT MIE SEUHAH PISAN (MIE SP) SUKABUMI
}

\author{
Adelia Athaya Dzakiyyah $^{1}$, Nor Norisanti ${ }^{2}$, Acep Syamsudin ${ }^{3}$ \\ Universitas Muhammadiyah Sukabumi ${ }^{1,2,3}$ \\ adeliathaya@gmail.com ${ }^{1}$
}

\begin{abstract}
ABSTRAK
Tujuan penelitian ini adalah untuk mengukur kekuatan dari social media dan word of mouth terhadap keputusan pembelian komsumen pada restorant Mie SP Sukabumi. Metode yang di gunakan dalam penelitian ini adalah deskriptif assosiatif dan pendekatan kuantitatif dengan regresi linear berganda sebagai teknik analisa data. Hasil dari penelitian ini menunjukan bahwa total pengaruh secara simultan hanya sebesar 4,5\% sedangakan sisanya sebesar 95,5\% dipengaruhi oleh variabel lain yang tidak di teliti dalam penelitian ini. Simpulan, social media tidak memberikan pengaruh yang positif dan signifikan terhadap keputusan pembelian, sedangkan word of mouth memberikan pengaruh kepada keputusan pembelian secara parsial.
\end{abstract}

Kata Kunci: Keputusan Pembelian, Social Media, Word of Mouth

\section{ABSTRACT}

The purpose of this study was to measure the strength of social media and word of mouth on consumer purchasing decisions at Mie SP Sukabumi restaurant. The method used in this research is associative descriptive and quantitative approaches with multiple linear regression as data analysis techniques. The results of this study indicate that the total effect simultaneously is only $4.5 \%$ while the remaining $95.5 \%$ is influenced by other variables not examined in this study. Conclusion, social media does not have a positive and significant influence on purchasing decisions, while word of mouth has an influence on purchasing decisions partially.

Keywords: Purchase Decision, Social Media, Word of Mouth

\section{PENDAHULUAN}

Perembangan zaman memunculkan banyak hal baru termasuk pada dunia bisnis kuliner. Karenanya, muncullah ide dan inovasi baru dalam membuat produk agar dapat menarik konsumen dan bisa menjadi salah satu alternatif ketika konsumen tersebut melakukan keputusan pembelian. Keputusan pembelian merupakan suatu konsep dalam perilaku pembelian dimana konsumen memutuskan untuk melakukan sesuatu seperti 
melakukan pembelian ataupun mengambil manfaat dari suatu produk atau jasa (Balawera, 2013). Pengambilan keputusan pembelian yang dilakukan oleh konsumen berawal dari kebutuhan dan dalam pemenuhan kebutuhan ini konsumen menemukan beberapa alternatif dan akan memilih sesuai dengan keinginannya.

Selain masalah perkembangan ide dan inovasi pada produk yang dibuat, cara promosi juga sudah mengalami banyak kemajuan. Saat ini, promosi sudah merambat kepada dunia internet atau media sosial. Metode promosi di media sosial ini sangat mudah dan praktis untuk pengusaha tanpa harus mengeluarkan biaya dan waktu yang banyak, hanya perlu mempublish barang yang dijual di media sosial. Informasi yang dikirim melalui promosi di media sosial juga akan dilihat oleh lebih banyak masyarakat.

Selain promosi di media sosial, metode promosi yang efektif dan efissien lainnya adalah word of mouth. Word of mouth adalah proses komunikasi berupa pemberian informasi atau rekomendasi suatu produk atau jasa yang bertujuan untuk memberikan informasi secara personal (Kotler, Keller, 2010) . Promosi word of mouth ini muncul ketika ada konsumen yang merasa puas dengan produk atau pelayanan dari suatu perusahaan. Kepuasan itulah yang mendorong konsumen tersebut untuk melakukan word of mouthi ini kepada orang-orang terdekatnya.

Di kota Sukabumi sendiri, terdapat banyak restoran yang menyajikan makanan dengan hasil ide yang kreatif dan juga digemari oleh banyak masyarakatnya, salah satunya adalah Mie SP. Mie SP adalah salah satu restorant melakukan promosi dengan menggunakan sosial media dan agar lebih banyak orang yang tau dan tertarik untuk membeli produknya.

\section{KAJIAN TEORI}

\section{Social Media}

Media sosial adalah tempat orang berkumpul untuk mencari sekaligus membagikan informasi. Media sosial lebih mudah digunakan karena hampir bahkan semua orang mempunyai alat komunikasi yang memadai untuk menggunakan sosial media. Media sosial juga lebih efisien karena tidak memerlukan dana yang banyak untuk melakukan pemasaran. 
Menurut Nasrullah (2017) "Media sosial adalah medium di internet yang memungkinkan pengguna mempresentasikan dirinya maupun berinteraksi, bekerja sama, berbagi, berkomunikasi dengan pengguna lain, dan membentuk ikatan sosial secara virtual”. Media sosial memiliki beberapa karakteristik yaitu:

Jaringan antar pengguna (network). Jaringan yang terbentuk antar pengguna yang membentuk komunitas.

Informasi (information). Informasi hal inti dan sangat penting sebab pengguna mengkreasikan representasi identitasnya, memproduksi konten, dan melakukan interaksi berdasarkan informasi.

Arsip (archive). Arsip menjadi sebuah karakter yang menjelaskan informasi telah tersimpan dan bisa diakses kapanpun dan melalui perangkat apapun.

Interaksi (interactivity). Secara sederhana interaksi yang terjadi di media sosial minimal berbentuk saling mengomentari atau memberikan tanda.

Simulasi sosial (simulation). Meski di media sosial interaksi terkihat mirip dengan realitas, akan tetapi interaksi yang terjadi adalah simulasi yang terkadang berbeda sama sekali.

Konten oleh pengguna (user generated content). Konten sepenuhnya berdasarkan kontribusi pengguna. Pengguna tidak hanya membuat konten, tapi juga mengkonsumsi konten yang diproduksi oleh pengguna lain.

Penyebaran (share). Penyebaran ini merupakan ciri khas dari media sosial yang menunjukan bahwa khalayak akan menyebarkan konten serta mengembangkannya.

\section{Word of Mouth}

Word of Mouth adalah rekomendasi seseorang kepada orang lain atas suatu produk atau jasa yang telah dia gunakan. Kotler dan Keller (2008) menjelaskan bahwa "word of mouth adalah suatu proses komunikasi yang berupa pemberian rekomendasi baik secara individu maupun kelompok terhadap suatu produk atau jasa yang bertujuan untuk memberikan informasi secara manual”.

Sernovitz (2009) menyebutkan bahwa ada 5 dimensi word of mouth, yaitu: 
Talkers. Pembicara dalam hal ini adalah konsumen yang sudah mengkonsumsi produk atau jasa. Terkadang, orang lain cenderung memilih produk atau jasa atas pengalaman orang lain.

Topics. WOM tercipta karena ada suatu perihal yang membuat mereka ingin berbicara mengenai produk atau jasa yang telah digunakan.

Tools. Setelah mereka mengetahui topik yang akan dibicarakan tentang produk atau jasa tersebut, dibutuhkan suatu alat untuk membantu agar pesan tersebut dapat berjalan.

Taking part. Taking part yaitu partisipasi dari perusahaan dalam menanggapi pertanyaan mengenai produk atau jasa tersebut dari para calon konsumen.

Tracking. Pengawasan diperlukan untuk word of mouth yang telah sehingga terdapat informasi banyaknya word of mouth positif atau word of mouth negative dari para konsumen.

\section{Keputusan Pembelian}

Dalam pelaksanaanya, keputusan pembelian dapat didefinisikan sebagai suatu keputusan yang dilakukan oleh konsumen untuk melakukan pembelian dan memilih satu dari berbagai alternatif yang tersedia untuk memenuhi kebutuhan dan keinginannya.

Kotler, Keller (2008) juga menjelaskan lima tahap proses pengambilan keputusan, antara lain:

Pengenalan Masalah. Keputusan pembelian muncul karena kebutuhan dan keinginan konsumen.

Pencarian Informasi. Setelah konsumen tersebut memahami akan kebutuhan dan keinginannya, mereka akan mencari informasi, baik yang berasal dari pengetahuan mereka maupun dari luar.

Evaluasi Alternatif. Konsumen mengevaluasi alternatif untuk memenuhi kebutuhan sesuai keinginan.

Keputusan Pembelian. Jika tidak ada hal lain yang mengganggu setelah konsumen menentukan pilihan, maka pembelian nyata adalah hasil akhir dari pencarian dan evaluasi yang telah dilakukan. 
Perilaku Pasca Pembelian. Jika konsumen menemukan kepuasan dari produk atau jasa yang dibelinya, maka keinginan untuk membeli ulang produk tersebut akan muncul dengan kuat.

\section{METODE PENELITIAN}

Penelitian ini menggunakan pendekatan manajemen pemasaran, khususnya membahas tetang social media dan word of mouth yang berpengaruh terhadap keutusan pembelian, serta menguji hipotesis yang sudah dirumuskan. Penelitian ini dilakukan di restorant Mie Seuhah Pisan Sukabumi dengan jumlah sampel 100. Teknik samplimg yang digunakan adalah teknik random sampling. Metode yang digunakan dalam penelitian ini yaitu metode deskriptif dan assosiatif dan pendekatan kuantitatif dengan regresi linear berganda sebagai teknik analisa data.

\section{HASIL PENELITIAN}

\section{Analisis Regresi Linear Berganda}

Table 1. Koefisien Determinasi

\begin{tabular}{lcrrr}
\hline \multicolumn{4}{c}{ Model Summary } \\
\hline Model & R & R Square & Adjusted R Square & Std. Error of the Estimate \\
\hline 1 & $.213^{\mathrm{a}}$ & .045 & & \\
a. Predictors: (Constant), Word of Mouth, Sosial Media & & \\
\hline b. Dependent Variable: Keputusan Pembelian & & \\
\hline
\end{tabular}

Sumber: data diolah peneliti.

Hasil dari table di atas menunjukan besarnya nilai $\mathrm{R}$ yang didapat dari table di atas adalah 0.213 berada dalam kategori 0,20 - 0,3999. Hal ini menunjukan bahwa terjadi hubungan yang rendah antara nilai social media dan word of mouth dengan keputusan pembelian konsumen. Adapun besarnya nilai $\mathrm{R}^{2}$ ( R Square) adalah 0,045 atau 4,5\%. Hasil tersebut menjelaskan bahwa Social Media dan Word of Mouth berpengaruh terhadap loyalitas merek hanya sebesar 4,5\%. sedangkan sisanya $95.5 \%$ dipengaruhi oleh variabel lain yang tidak dimasukan dalam jenis model penelitian ini. 
Table 2 Hasil Analisis Regresi Linear Berganda

\begin{tabular}{|c|c|c|c|c|c|c|c|}
\hline \multirow[b]{3}{*}{ Model } & \multicolumn{5}{|c|}{ Coefficients $^{\mathrm{a}}$} & \multirow{2}{*}{\multicolumn{2}{|c|}{$\begin{array}{c}\text { Collinearity } \\
\text { Statistics }\end{array}$}} \\
\hline & \multicolumn{2}{|c|}{$\begin{array}{c}\text { Unstandardized } \\
\text { Coefficients }\end{array}$} & \multirow{2}{*}{$\begin{array}{c}\text { Standardized } \\
\text { Coefficients } \\
\text { Beta }\end{array}$} & \multirow[b]{2}{*}{$\mathrm{t}$} & \multirow[b]{2}{*}{ Sig. } & & \\
\hline & B & Std. Error & & & & Tolerance & VIF \\
\hline (Constant) & 13.457 & 3.489 & & 3.857 & .000 & & \\
\hline $\begin{array}{l}\text { Sosial } \\
\text { Media }\end{array}$ & .026 & .088 & .030 & .300 & .765 & .997 & 1.003 \\
\hline $\begin{array}{l}\text { Word of } \\
\text { Mouth }\end{array}$ & .256 & .120 & .212 & 2.139 & .035 & .997 & 1.003 \\
\hline
\end{tabular}

Berdasarkan dari tabel diatas telah di dapatkan hasil pengolahan data dan selanjutnya hasil data tersebut di rumuskan sesuai dengan model persamaan regresi linear berganda sebagai berikut:

$$
\begin{gathered}
\mathbf{Y}=\mathrm{a}+\mathrm{b} 1 \mathrm{X} 1+\mathrm{b} 2 \mathrm{X} 2+\mathrm{e} \\
\mathrm{Y}=13,457+0,026 \mathrm{X} 1+0,256 \mathrm{X} 2+\varepsilon
\end{gathered}
$$

$\mathrm{Y}=$ Keputusan Pembelian $\quad \mathrm{X} 1=$ Social Media

X2 $=$ Word of Mouth $\quad \varepsilon=$ Residual

Konstanta (a) memiliki nilai sebesar 13.457 ini menunjukkan jika Social Media (X1) dan Word of mouth (X2) bernilai nol maka Keputusan Pembelian (Y) memiliki nilai sebesar 13.457. Variabel X1 memiliki nilai koefisien regresi positif sebesar 0,026, dapat diartikan bahwa jika variabel independen lain nilainya tetap atau tidak berubah, maka setiap kenaikan 1 poin atau $1 \%$ maka variabel $\mathrm{Y}$ akan mengalami kenaikan sebesar 0,026. Semakin meningkat nilai X1 (Social Media) maka semakin meningkat Y (keputusan pembelian). Variabel X2 memiliki nilai koefisien regresi positif sebesar 0,256, dapat diartikan bahwa jika variabel independen lain nilainya tetap atau tidak berubah, maka setiap kenaikan 1 poin atau $1 \%$ variabel $\mathrm{Y}$ akan meningkatkan minat beli sebesar 0,256 . Semakin meningkat nilai X2 (word of mouth) maka akan meningkatkan Y (keputusan pembelian). 


\section{Uji Signifikasi Secara Simultan (F-test)}

Table 3 Hasil Uji F

\begin{tabular}{|c|c|c|c|c|c|c|}
\hline \multicolumn{7}{|c|}{ ANOVA $^{\mathrm{a}}$} \\
\hline \multicolumn{2}{|c|}{ Model } & Sum of Squares & Df & Mean Square & $\mathrm{F}$ & Sig. \\
\hline \multirow[t]{3}{*}{1} & Regression & 75.853 & 2 & 37.926 & 2.306 & $.105^{\mathrm{b}}$ \\
\hline & Residual & 1595.507 & 97 & 16.449 & & \\
\hline & Total & 1671.360 & 99 & & & \\
\hline \multicolumn{7}{|c|}{ a. Dependent Variable: Keputusan Pembelian } \\
\hline \multicolumn{7}{|c|}{ b. Predictors: (Constant), Word of Mouth, Sosial Media } \\
\hline
\end{tabular}

Pada penelitian ini menggunakan nilai signifikansi sebesar 0.1 dan nilai $\mathrm{F}$ tabel dari dua variabel bebas dan 100 responden adalah 2.36. Nilai $\mathrm{F}_{\text {hitung }}$ adalah 2.306, karena nilai $\mathrm{F}_{\text {hitung }} 2.306 \leq \mathrm{F}$ tabel 2.36, dan dilihat juga nilai regresi memiliki tingkat signifikan 0.105 nilai ini lebih besar dari 0.1, maka dapat sidapat disimpulkan bahwa social media dan word of mouth secara bersama-sama (simultan) memiliki pengaruh yang positif tetapi tidak signifikan terhadap keputusan pembelian konsumen.

\section{Uji Signifikasi Secara Parsial (T-test)}

Table 4 Hasil Uji T

\begin{tabular}{|c|c|c|c|c|c|c|}
\hline \multicolumn{7}{|c|}{ Coefficients $^{\text {ar] }}$} \\
\hline \multirow{2}{*}{\multicolumn{2}{|c|}{ Model }} & \multicolumn{2}{|c|}{$\begin{array}{c}\text { Unstandardized } \\
\text { Coefficients }\end{array}$} & \multirow{2}{*}{$\begin{array}{c}\text { Standardized } \\
\text { Coefficients } \\
\text { Beta }\end{array}$} & \multirow[b]{2}{*}{$\mathrm{t}$} & \multirow{3}{*}{ Sig. } \\
\hline & & B & Std. Error & & & \\
\hline 1 & (Constant) & 13.457 & 3.489 & & 3.857 & \\
\hline & Sosial Media & .026 & .088 & .030 & .300 & .765 \\
\hline & Word of Mouth & .256 & .120 & .212 & 2.139 & .035 \\
\hline
\end{tabular}

Sumber: data diolah peneliti.

Berdasarkan table 4 di atas, dari hasil uji hipotesis uji $\mathrm{T}$ yang dilakukan dapat dilihat bahwa variabel nilai social media nilai sig. $0,765>0,1$; nilai $t_{\text {hitung }} 0,3<t_{\text {tabel }}$ 1.66055, artinya nilai social media tidak berpengaruh signifikan secara parsial terhadap keputusan pembelian konsumen. Variabel word of mouth nilai sig. $0,035<0,1$; nilai 
$t_{\text {hitung }} 2,139>t_{\text {tabel }}$ 1.66055, artinya word of mouth berpengaruh positif dan signifikan secara parsial terhadap keputusan pembelian konsumen.

\section{PEMBAHASAN}

\section{Hasil Uji Hipotesis}

Social Media tidak berpengaruh positif dan signifikan terhadap keputusan pembelian konsumen. Hal ini dapat dibuktikan dari hasil pengujian uji t yang menunjukan nilai sig. $0,765>0,1$; nilai $t_{\text {hitung }} 0,3<t_{\text {tabel }} 1.66055$, maka dapat disimpulkan bahwa social media tidak memberikan pengaruh yang positif dan signifikan terhadap keputusan pembelian konsumen.

Word of Mouth berpengaruh secara positif dan signifikan terhadap keputusan pembelian konsumen. Hal ini dapat dibuktikan dari hasil pengujian uji t yang menunjukan nilai sig. $0,035<0,1$; nilai $t_{\text {hitung }} 2,139>\mathrm{t}_{\text {tabel }}$ 1.66055, maka dapat diambil kesimpulan bahwa hasil word of mouth memberikan pengaruh yang positif dan signifikan terhadap keputusan pembelian konsumen.

Social media dan word of mouth tidak memberikan pengaruh yang positif dan signifikan terhadap keputusan pembelian secara simultan. Hal ini dapat dilihat dari hasil pengujian uji $\mathrm{F}$ yang menunjukan nilai sig. $0.105>0.1$; nilai $\mathrm{F}_{\text {hitung }} 2.306<\mathrm{F}_{\text {tabel }} 2.36$, maka dapat disimpulkan bahwa $\mathrm{H}_{3}$ ditolak. Hal ini menyimpulkan bahwa Social media dan word of mouth memberikan pengaruh yang positif tetapi tidak signifikan terhadap keputusan pembelian secara simultan.

Selain masalah perkembangan ide dan inovasi pada produk yang dibuat, cara promosi juga sudah mengalami banyak kemajuan. Saat ini, promosi sudah merambat kepada dunia internet atau media sosial. Metode promosi di media sosial ini sangat mudah dan praktis untuk pengusaha tanpa harus mengeluarkan biaya dan waktu yang banyak, hanya perlu mempublish barang yang dijual di media sosial. Informasi yang dikirim melalui promosi di media sosial juga akan dilihat oleh lebih banyak masyarakat.

Selain promosi di media sosial, metode promosi yang efektif dan efissien lainnya adalah word of mouth. Word of mouth adalah proses komunikasi berupa pemberian 
informasi atau rekomendasi suatu produk atau jasa yang bertujuan untuk memberikan informasi secara personal (Kotler, Keller, 2010). Promosi word of mouth ini muncul ketika ada konsumen yang merasa puas dengan produk atau pelayanan dari suatu perusahaan. Kepuasan itulah yang mendorong konsumen tersebut untuk melakukan word of mouthi ini kepada orang-orang terdekatnya.

\section{SIMPULAN}

1. Secara parsial, social media tidak berpengaruh positif dan signifikan terhadap keputusan pembelian konsumen restorant Mie SP Sukabumi

2. Secara parisal, word of mouth berpengaruh positif dan signifikan terhadap keputusan pembelian konsumen restorant Mie SP Sukabumi

3. Berdasarkan pengujian regresi berganda dan pengujian melalui uji $\mathrm{F}$, social media dan word of mouth, secara simultan, memberikan pengaruh positif tetapi tidak signifikan terhadap keputusan pembelian konsumen restorant Mie SP Sukabumi

\section{DAFTAR PUSTAKA}

Balawera, A. (2013). Green Marketing dan Corporate Social Responsibility Pengaruhnya terhadap Keputusan Pembelian Konsumen melalui Minat Membeli Produk Organik di Freshmart Kota Manado. Jurnal EMBA, 1(4), 2117-2129

Kotler, P., \& Keller, K. L. (2010). Manajemen Pemasaran (edisi 13) Jilid II. Jakarta: Penerbit Erlangga

Kotler, P., \& Keller, K. L. (2008). Manajemen Pemasaran (edisi 13) Jilid I. Jakarta: Penerbit Erlangga

Nasrullah, R. (2017). Media Sosial (Perspektif Komunikasi, Budaya, dan Sosioteknologi). Bandung: Simbiosa Rekatama Media

Sernovitz, A. (2009). Word of Mouth Marketing: How Smart Companies Get People Talking (Revised Edition). New York : Kaplan Publishing 